\title{
Controls on the isotopic composition of microbial
} methane

\author{
Jonathan Gropp, ${ }^{1 *}$ Qusheng Jin, ${ }^{2}$ Itay Halevy ${ }^{1}$ \\ ${ }^{1}$ Department of Earth and Planetary Sciences, Weizmann Institute of Science, Rehovot, Israel \\ ${ }^{2}$ Department of Earth Sciences, University of Oregon, Eugene, Oregon, USA \\ *To whom correspondence should be addressed; E-mail: jonathan.gropp@weizmann.ac.il.
}

\begin{abstract}
Microbial methane production (methanogenesis) is responsible for more than half of the annual emission of this major greenhouse gas to the atmosphere. Though the stable isotopic composition of methane is often used to characterize its sources and sinks, empirical descriptions of the isotopic signature of methanogenesis currently limit such attempts. We developed a biochemical-isotopic model of methanogenesis by $\mathrm{CO}_{2}$ reduction, which predicts carbon and hydrogen isotopic fractionations, and clumped isotopologue distributions, as functions of the cell's environment. We mechanistically explain multiple-isotopic patterns in laboratory and natural settings and show that such patterns constrain the in-situ energetics of methanogenesis. Combining our model with environmental data, we infer that in almost all marine environments and gas deposits, energy-limited methanogenesis operates close to chemical and isotopic equilibrium.
\end{abstract}


Methane $\left(\mathrm{CH}_{4}\right)$ is a major greenhouse gas, with both natural and anthropogenic sources $(1)$. The primary natural source of biogenic methane emissions is archaeal methanogenesis in anoxic environments (2), about a third of which is hydrogenotrophic (reduction of $\mathrm{CO}_{2}$ with dihydrogen, $\mathrm{H}_{2}$; Ref. 3). Strong isotopic discrimination during biological and abiotic methane formation has motivated the use of methane hydrogen and carbon isotopes to trace its production and consumption processes, construct global methane budgets and evaluate its climatic impacts $(1,4,5)$. Current organism-level models that rely on isotopic mass balance can explain part of the observed range of microbial isotopic discrimination (6-9), but to date, such models have prescribed rather than resolved the microbial biochemistry. It has been difficult, therefore, to distinguish between different methane sources, different modes and extents of environmental methane cycling, and different environmental controls on the microbial isotope discrimination as drivers of observed variations in the isotopic composition of methane. To constrain the microbial component of such variations, we developed and analyzed a full metabolic-isotopic model of hydrogenotrophic methanogenesis, which predicts the isotopic discrimination and its relation to the thermodynamic drive of this pathway (the Gibbs free energy of the net reaction $4 \mathrm{H}_{2}+\mathrm{CO}_{2} \rightleftharpoons \mathrm{CH}_{4}+2 \mathrm{H}_{2} \mathrm{O}, \Delta \mathrm{G}_{\text {net }}$ ) and to cell-specific methanogenesis rates in laboratory cultures. Extending our analysis to energy-limited conditions, which are prevalent in natural environments, our model reveals the environmental and metabolic controls on the isotopic composition of methane.

Accounting for the kinetics and thermodynamics of enzymatically-catalyzed reactions in hydrogenotrophic methanogenesis (details in the Supplementary Materials, SM), we constructed mass balance equations for the intracellular metabolites in the pathway (Fig. 1A). Given extracellular concentrations of $\mathrm{CO}_{2}, \mathrm{H}_{2}$ and $\mathrm{CH}_{4}$, and $\mathrm{pH}$, which define $\Delta \mathrm{G}_{\text {net }}$, these equations are solved for the steady-state concentrations of the intracellular metabolites (fig. S1). At this steady state, the model links metabolite concentrations to the net rate of methanogenesis, and to the gross forward and reverse rates of the individual reactions. We calibrated our metabolic model to available measurements of specific methanogenesis rates and their relation to $\mathrm{H}_{2}$ concentrations in the $\mu \mathrm{M}$ to $\mathrm{mM}$ range (fig. S2; SM). The metabolic model accounts for electron transfer from $\mathrm{H}_{2}$ to the in- 

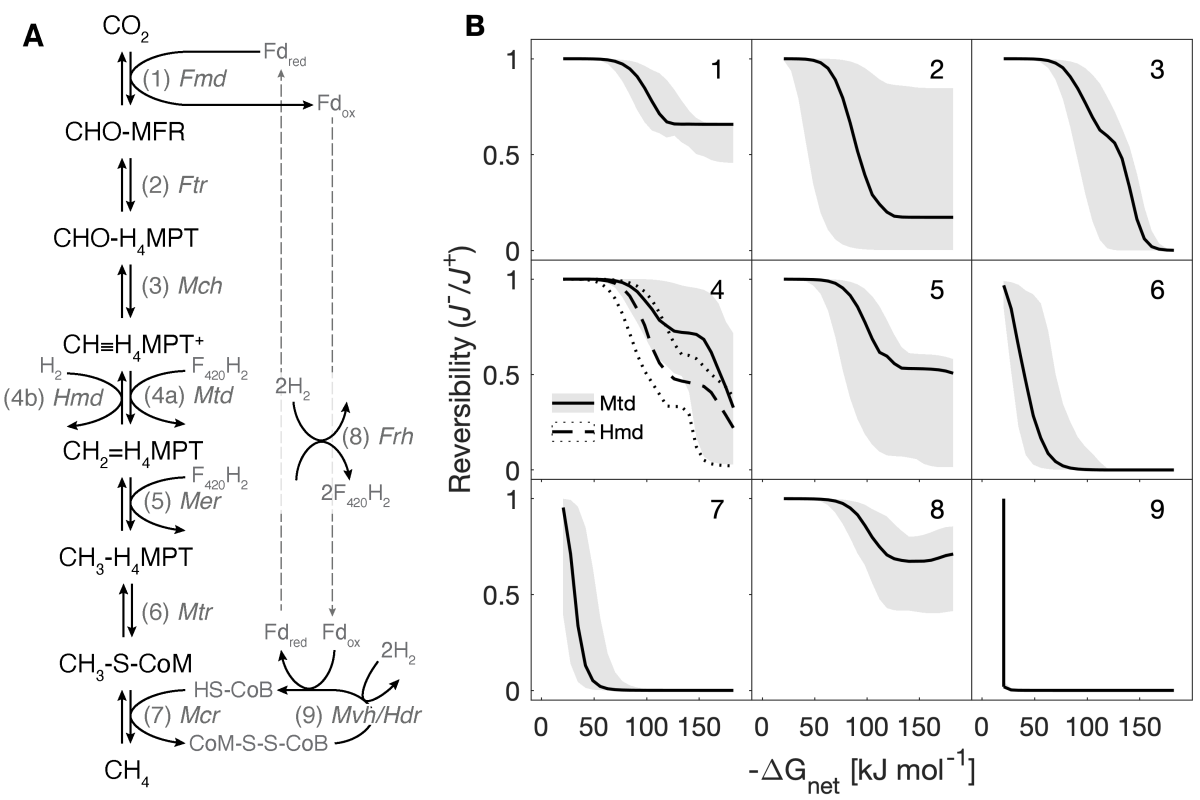

Figure 1: A metabolic model of hydrogenotrophic methanogenesis. (A) Schematic pathway. Abbreviated enzyme names are in italics (table S1). (B) Individual reaction reversibility $\left(J_{i}^{-} / J_{i}^{+}\right)$against $\Delta \mathrm{G}_{\text {net }}$. The subplots in panel B are numbered in accordance with panel A and table S1. The black lines are the median of $10^{3}$ model simulations, and envelopes represent $95 \%$ of model results. The uncertainty originates from the enzyme kinetic parameters. Simulations were carried out at $\left[\mathrm{H}_{2}\right]$ of $1 \mathrm{nM}$ to $10 \mathrm{mM}$, and typical experimental $\left[\mathrm{CO}_{2}\right]$ and $\left[\mathrm{CH}_{4}\right]$ of $10 \mathrm{mM}$ and $10 \mu \mathrm{M}$, respectively.

termediate metabolites through three electron carriers, cofactor $\mathrm{F}_{420}$, coenzyme B (HS-CoB), and ferredoxin $(\mathrm{Fd})$, and we validated the calibrated model predictions of the oxidation state of these electron carriers against available experimental and theoretical estimates (SM).

The calibrated and validated biochemical model forms the basis for the metabolic-isotopic coupling. With increasing $\mathrm{H}_{2}$ concentrations, $\Delta \mathrm{G}_{\text {net }}$ becomes increasingly negative, and the individual reactions in the pathway depart from equilibrium to various extents (Fig.1B). We quantify the departure from equilibrium by the individual reaction reversibility, defined as the ratio of the reverse to forward gross rates of that reaction and related to its actual transformed Gibbs free energy, $J_{i}^{-} / J_{i}^{+}=\exp \left(\Delta \mathrm{G}_{\mathrm{i}}^{\prime} / \mathrm{RT}\right)(10-12)$. For net forward methanogenesis rates, the reversibility of individual reactions varies between zero (a near-unidirectional, kinetically controlled reaction) and unity (a near-equilibrium reaction). Some reactions do not fully depart from reversibility in the explored $\Delta \mathrm{G}_{\text {net }}$ space (e.g., the Frh-catalyzed reduction of $\mathrm{F}_{420}$ ), whereas others depart from reversibility at 
$\Delta \mathrm{G}_{\text {net }}$ as modestly negative as $-15 \mathrm{~kJ} \mathrm{~mol}^{-1}$ (e.g., the Mvh/Hdr, Mcr and Mtr-catalyzed reactions). This differential response is a combined function of the reaction thermodynamics, expressed as the standard-state transformed Gibbs free energy $\left(\Delta \mathrm{G}_{\mathrm{i}}^{\prime 0}\right)$, and the enzyme kinetics, specifically the metabolic rate capacity $\left(V^{+}\right)$and Michaelis constants $\left(K_{M}\right)$. Neither $\Delta \mathrm{G}_{\mathrm{i}}^{\prime 0}$ nor $V^{+}$and $K_{M}$ in isolation predict the pattern of differential departure from equilibrium—coupled thermodynamics and kinetics must be considered.

The net isotopic fractionation $(\alpha, \mathrm{SM})$ expressed in an individual (bio)chemical reaction may vary between thermodynamic equilibrium and kinetic end-members, associated respectively with a reversible reaction and unidirectional forward reaction to form the reaction product. With the reversibilities calculated in the metabolic model and with values assigned to the equilibrium and kinetic isotopic fractionation factors (EFFs and KFFs, respectively) of the individual reactions, the net isotopic fractionation between the pathway substrates and products may be calculated (13, 14). We calibrated the relations between $\Delta \mathrm{G}_{\text {net }}$ and the resulting net carbon and hydrogen isotopic fractionations against experimental data, then used the calibrated model to determine the relation between $\Delta \mathrm{G}_{\text {net }}$ and the abundance of doubly substituted ("clumped") methane isotopologues, which has yet to be systematically explored in experiments.

In laboratory cultures, the $\mathrm{CO}_{2}-\mathrm{CH}_{4}$ carbon isotope fractionation $\left({ }^{13} \varepsilon_{\mathrm{CO}_{2}-\mathrm{CH}_{4}}\right.$, where $\varepsilon=1-\alpha$ $\left[\%\right.$ o]) is inversely related to $\Delta \mathrm{G}_{\text {net }}\left(8,15-19\right.$, fig. S3A). At near-zero $\Delta \mathrm{G}_{\text {net }}$, the individual reactions in the pathway operate close to equilibrium $\left(J_{i}^{-} / J_{i}^{+} \rightarrow 1\right)$, and our model predicts ${ }^{13} \varepsilon_{\mathrm{CO}_{2}-\mathrm{CH}_{4}}$ close to the temperature-dependent isotopic equilibrium fractionation $\left({ }^{13} \varepsilon_{\mathrm{CO}_{2}-\mathrm{CH}_{4}}^{\mathrm{eq}}\right)$. When $\Delta \mathrm{G}_{\mathrm{net}}$ becomes slightly negative, ${ }^{13} \varepsilon_{\mathrm{CO}_{2}-\mathrm{CH}_{4}}$ peaks to larger-than-equilibrium values of $80-100 \%$ at $\approx-45$ $\mathrm{kJ} \mathrm{mol}^{-1}$, followed by a gradual decline to $\approx 30 \%$ reached at $\Delta \mathrm{G}_{\mathrm{net}}$ of $\approx-120 \mathrm{~kJ} \mathrm{~mol}^{-1}$ (Fig. $2 \mathrm{~A}$ ). Such larger-than-equilibrium ${ }^{13} \varepsilon_{\mathrm{CO}_{2}-\mathrm{CH}_{4}}$ values have been observed in several experimental and environmental datasets and have yet to be explained mechanistically. Our model reveals that this $\Delta \mathrm{G}_{\text {net }}{ }^{13}{ }^{13} \varepsilon_{\mathrm{CO}_{2}-\mathrm{CH}_{4}}$ relation is controlled by the landscape of departure from equilibrium of the individual reactions in the pathway. The carbon reaction network in methanogenesis is linear. In such networks, near-unidirectionality of an individual reaction $\left(J_{i}^{-} / J_{i}^{+} \rightarrow 0\right)$ leads to expression 
of that reaction's KFF and suppresses isotopic fractionation associated with downstream reactions (14). The Mcr-catalyzed reaction's KFF ( $\approx 40 \%$ o, Ref. 20$)$ is larger than its EFF ( $\approx 1 \%$ o, Ref. 21$)$. As this reaction departs from equilibrium, the peak in ${ }^{13} \varepsilon_{\mathrm{CO}_{2}-\mathrm{CH}_{4}}$ reflects a sum of its $\mathrm{KFF}$ and the EFFs of upstream reactions, with the exception of the Mtr-catalyzed reaction, which also partially departs from equilibrium (Fig. 1B). The ${ }^{13} \varepsilon_{\mathrm{CO}_{2}-\mathrm{CH}_{4}}$ floor at $\Delta \mathrm{G}_{\text {net }}$ more negative than $\approx-120$ $\mathrm{kJ} \mathrm{mol}^{-1}$ (Fig. 2A) is defined by partial expression of the KFFs of Ftr and Fmd, and suppression of the isotopic fractionations associated with downstream reactions.

At large-negative $\Delta \mathrm{G}_{\text {net }}$ values ${ }^{13} \varepsilon_{\mathrm{CO}_{2}-\mathrm{CH}_{4}}$ is sensitive also to the extracellular partial pressure of $\mathrm{CO}_{2}\left(p \mathrm{CO}_{2}\right)$. At a steady state, intracellular $\mathrm{CO}_{2}$ utilization is exactly matched by net $\mathrm{CO}_{2}$ diffusion across the membrane. This net diffusive flux is the difference between large gross fluxes (into and out of the cell) when $p \mathrm{CO}_{2}$ is high, and smaller gross fluxes at lower $p \mathrm{CO}_{2}$. Thus, the reversibility of net diffusion is low at low $p \mathrm{CO}_{2}$, and suppression of downstream net carbon isotopic fractionation results in small ${ }^{13} \varepsilon_{\mathrm{CO}_{2}-\mathrm{CH}_{4}}$. The dependence of ${ }^{13} \varepsilon_{\mathrm{CO}_{2}-\mathrm{CH}_{4}}$ on $p \mathrm{CO}_{2}$ explains the smallest net fractionations observed in laboratory cultures (lower bound of red envelope in Fig. 2B, Ref. 17), as well as the dependence of ${ }^{13} \varepsilon_{\mathrm{CO}_{2}-\mathrm{CH}_{4}}$ on $\mathrm{pH}$ in hyperalkaline settings $(22,23)$.

The $\mathrm{CH}_{4}-\mathrm{H}_{2} \mathrm{O}$ hydrogen isotopic fractionation $\left({ }^{2} \varepsilon_{\mathrm{CH}_{4}-\mathrm{H}_{2} \mathrm{O}}\right)$ in laboratory cultures is $\approx 200 \%$ o more negative than the temperature-dependent isotopic equilibrium fractionation $\left({ }^{2} \varepsilon_{\mathrm{CH}_{4}-\mathrm{H}_{2} \mathrm{O}}^{\mathrm{eq}}\right)$, and existing observations suggest that it does not display a clear dependence on $\Delta \mathrm{G}_{\text {net }}(8,15,18,24$, 25, fig. S3B). Unlike the linear carbon reaction network, the hydrogen reaction network has four branches, each of which has the potential for hydrogen atom exchange between pathway intermediates and $\mathrm{H}_{2} \mathrm{O}$. Therefore, departure from equilibrium of one of the hydrogen atom exchange reactions does not preclude $\mathrm{CH}_{4}-\mathrm{H}_{2} \mathrm{O}$ hydrogen isotopic equilibrium. Specifically, the Mvh/Hdrcatalyzed reaction is near-irreversible at $\Delta \mathrm{G}_{\text {net }}$ values as high as $-25 \mathrm{~kJ} \mathrm{~mol}^{-1}$ (Fig. 1B), yet at this $\Delta \mathrm{G}_{\text {net }}$ value ${ }^{2} \varepsilon_{\mathrm{CH}_{4}-\mathrm{H}_{2} \mathrm{O}} \simeq{ }^{2} \varepsilon_{\mathrm{CH}_{4}-\mathrm{H}_{2} \mathrm{O}}^{\mathrm{eq}}$ (Fig. $2 \mathrm{C}$ ), and this arises from the high reversibility of the other hydrogen atom exchange reactions in the pathway. Only when the Mcr- and Mtr-catalyzed reactions sufficiently depart from reversibility $\left(\Delta \mathrm{G}_{\text {net }} \leq-30 \mathrm{~kJ} \mathrm{~mol}^{-1}\right)$, cutting off $\mathrm{CH}_{4}$ and $\mathrm{HS}-\mathrm{CoB}$ from exchange with upstream intermediates that are close to hydrogen isotope equilibrium with 

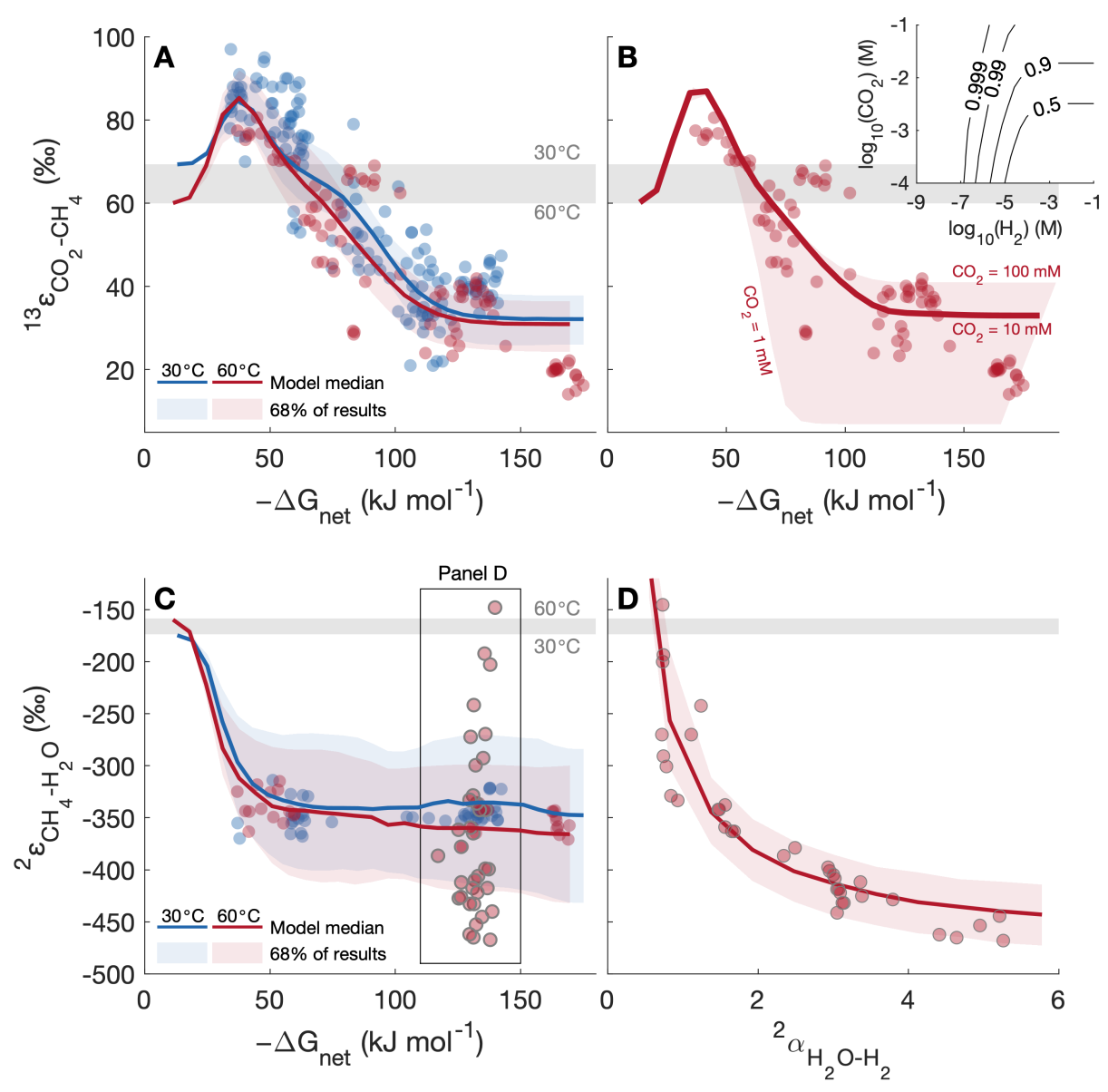

Figure 2: Model-laboratory culture comparison of bulk carbon and hydrogen isotopic fractionation. Mesophilic $\left(30-40^{\circ} \mathrm{C}\right.$, blue circles) and thermophilic $\left(\geq 55^{\circ} \mathrm{C}\right.$, red circles) experimental data and model results (lines and envelopes) at $30^{\circ} \mathrm{C}$ (blue) and $60^{\circ} \mathrm{C}$ (red), and the equilibrium isotopic fractionation (gray envelopes). $(\mathbf{A}, \mathbf{C}){ }^{13} \varepsilon_{\mathrm{CO}_{2}}-\mathrm{CH}_{4}$ and ${ }^{2} \varepsilon_{\mathrm{CH}_{4}-\mathrm{H}_{2} \mathrm{O}}$ against $\Delta \mathrm{G}_{\text {net }}$. (B) ${ }^{13} \varepsilon_{\mathrm{CO}_{2}-\mathrm{CH}_{4}}$ against extracellular $\mathrm{CO}_{2}$ concentrations ([CO $\mathrm{CO}_{2}$ (out) $]$ ). Contours in the

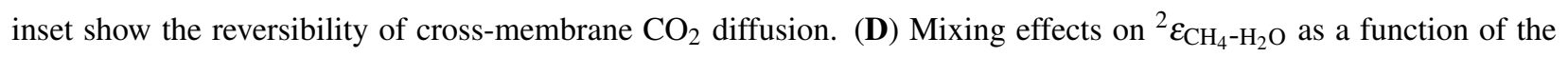
$\mathrm{H}_{2} \mathrm{O}-\mathrm{H}_{2}$ isotopic fractionation $\left({ }^{2} \alpha_{\mathrm{H}_{2} \mathrm{O}-\mathrm{H}_{2}}\right)$, compared to laboratory culture data $(8)$.

${ }_{112} \mathrm{H}_{2} \mathrm{O}$, does ${ }^{2} \varepsilon_{\mathrm{CH}_{4}-\mathrm{H}_{2} \mathrm{O}}$ depart from ${ }^{2} \varepsilon_{\mathrm{CH}_{4}-\mathrm{H}_{2} \mathrm{O}}^{\mathrm{eq}}$ (Fig. 2C). At $\Delta \mathrm{G}_{\text {net }}$ more negative than $-40 \mathrm{~kJ} \mathrm{~mol}^{-1}$ 113 the KFFs of Mcr, Mtr and Mvh/Hdr control ${ }^{2} \varepsilon_{\mathrm{CH}_{4}-\mathrm{H}_{2} \mathrm{O}}$ (fig. S4). Overall, our model reveals a clear ${ }_{114}{ }^{2} \varepsilon_{\mathrm{CH}_{4}-\mathrm{H}_{2} \mathrm{O}}-\Delta \mathrm{G}_{\text {net }}$ relation, which has not been accessed by the range of $\Delta \mathrm{G}_{\text {net }}$ explored in laboratory 115 cultures to date. The apparent invariance of ${ }^{2} \varepsilon_{\mathrm{CH}_{4}-\mathrm{H}_{2} \mathrm{O}}$ at $\Delta \mathrm{G}_{\text {net }}$ more negative than $-40 \mathrm{~kJ} \mathrm{~mol}^{-1}$ represents a complex, $\Delta \mathrm{G}_{\text {net }}$-dependent combination of isotope effects associated with the enzymes

117 in the pathway. 
The hydrogen atom added to $\mathrm{CH}-\mathrm{H}_{4} \mathrm{MPT}$ may come from $\mathrm{H}_{2} \mathrm{O}$ in the Mtd-catalyzed reaction, or from $\mathrm{H}_{2}$ in the Hmd-catalyzed reaction (Fig. 1A; 26). Thus, up to one quarter of the hydrogen atoms in methane may come from $\mathrm{H}_{2}$, depending on the relative activity of Mtd and Hmd. High $\mathrm{H}_{2}$ concentrations favor high methanogenesis rates and Hmd activity. Under these conditions, and especially in the case of $\mathrm{H}_{2}-\mathrm{H}_{2} \mathrm{O}$ isotopic disequilibrium, ${ }^{2} \varepsilon_{\mathrm{CH}_{4}-\mathrm{H}_{2} \mathrm{O}}$ may vary in response to variations in the hydrogen isotopic composition of $\mathrm{H}_{2}$. Our model captures this behavior, as observed in culture experiments with $1 \mathrm{mM}\left[\mathrm{H}_{2}\right]$ and at $60^{\circ} \mathrm{C}(8,25)$, displaying ${ }^{2} \varepsilon_{\mathrm{CH}_{4}-\mathrm{H}_{2} \mathrm{O}}$ values between $-145 \%$ o and $-480 \%$ o, which inversely covary with the $\mathrm{H}_{2} \mathrm{O}-\mathrm{H}_{2}$ isotopic fractionation (Fig. 2D).

Our predicted trajectories for departure from equilibrium ${ }^{13} \varepsilon_{\mathrm{CO}_{2}-\mathrm{CH}_{4}}$ and ${ }^{2} \varepsilon_{\mathrm{CH}_{4}-\mathrm{H}_{2} \mathrm{O}}$ values may explain observations of near-equilibrium ${ }^{13} \varepsilon_{\mathrm{CO}_{2}-\mathrm{CH}_{4}}$ values concurrent with clearly disequilibrium ${ }^{2} \varepsilon_{\mathrm{CH}_{4}-\mathrm{H}_{2} \mathrm{O}}$ values, which have been previously explained by a decoupling of the carbon and hydrogen isotopic systems in methanogenesis $(8,27)$. We suggest instead, that the measured ${ }^{13} \varepsilon_{\mathrm{CO}_{2}-\mathrm{CH}_{4}}$ values did not reflect isotopic equilibrium, but the descending branch from the ${ }^{13} \varepsilon_{\mathrm{CO}_{2}-\mathrm{CH}_{4}}$ maximum (at $\Delta \mathrm{G}_{\text {net }} \approx-40 \mathrm{~kJ} \mathrm{~mol}^{-1}$ ) with increasingly negative $\Delta \mathrm{G}_{\text {net }}$.

The distributions of the clumped isotopologues of $\mathrm{CH}_{4}\left(\Delta^{13} \mathrm{CH}_{3} \mathrm{D}\right.$ and $\left.\Delta^{12} \mathrm{CH}_{2} \mathrm{D}_{2}\right)$ depend on the methane formation temperature (6). However, applications of methane clumped isotopes to constrain its formation are complicated by source mixing and disequilibrium effects $(7,28)$. The dependence of $\Delta^{13} \mathrm{CH}_{3} \mathrm{D}$ and $\Delta^{12} \mathrm{CH}_{2} \mathrm{D}_{2}$ on $\Delta \mathrm{G}_{\text {net }}$ has not been determined experimentally, and similar to bulk carbon isotopes, our model predicts non-monotonic departure from clumped isotopic equilibrium (fig. S5), unlike previous estimates of these relations $(7,29)$. As $\Delta \mathrm{G}_{\text {net }}$ becomes negative, both $\Delta^{13} \mathrm{CH}_{3} \mathrm{D}$ and $\Delta^{12} \mathrm{CH}_{2} \mathrm{D}_{2}$ values decrease from the expected equilibrium compositions, and $\Delta^{12} \mathrm{CH}_{2} \mathrm{D}_{2}$ becomes anti-clumped (i.e., $<0 \%$ ) due to expression of the KFFs of the Mcr- and Mtr-catalyzed reactions. After the initial decrease in $\Delta^{13} \mathrm{CH}_{3} \mathrm{D}$ and $\Delta{ }^{12} \mathrm{CH}_{2} \mathrm{D}_{2}$, both increase with increasingly negative $\Delta \mathrm{G}_{\text {net }}$ to values almost as high as the equilibrium values. This behavior has two implications. First, there is a range of $\Delta \mathrm{G}_{\text {net }}\left(\approx-75\right.$ to $\left.-55 \mathrm{~kJ} \mathrm{~mol}^{-1}\right)$ over which $\Delta^{13} \mathrm{CH}_{3} \mathrm{D}$ values may give the false appearance of proximity to isotopic equilibrium. Second, there is a range of $\Delta \mathrm{G}_{\text {net }}\left(\approx-100\right.$ to $\left.-20 \mathrm{~kJ} \mathrm{~mol}^{-1}\right)$ over which $\Delta^{13} \mathrm{CH}_{3} \mathrm{D}$ and $\Delta^{12} \mathrm{CH}_{2} \mathrm{D}_{2}$ cannot uniquely 

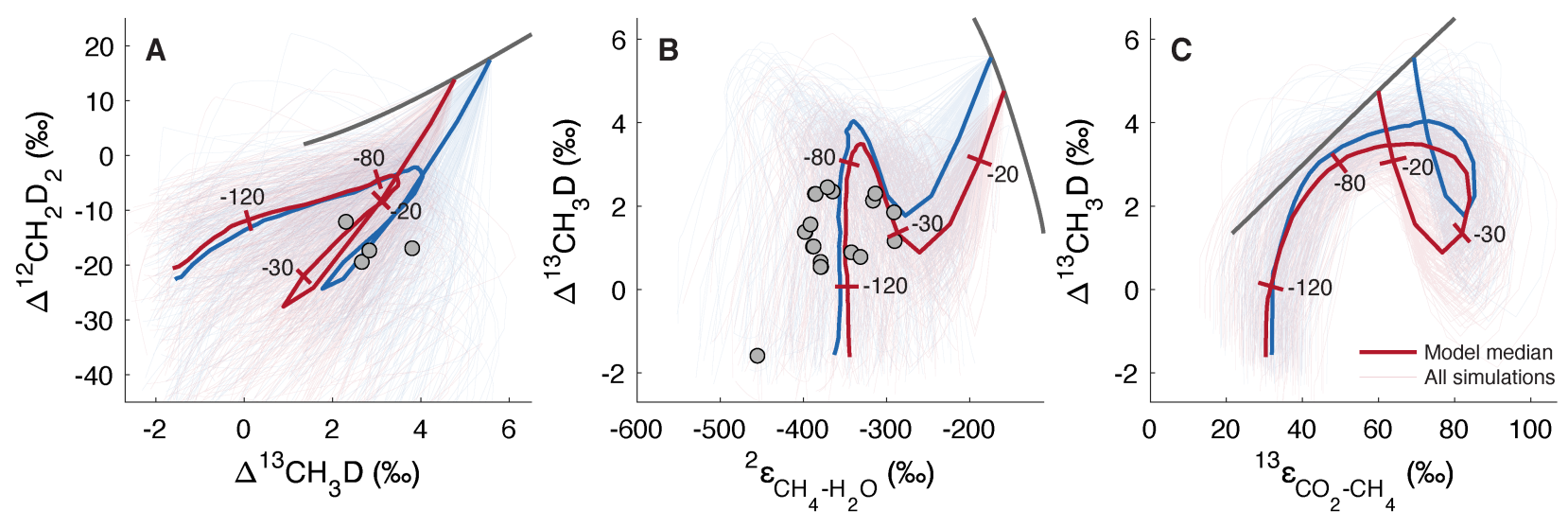

Figure 3: Model-laboratory culture comparison of clumped isotopologue abundances. Experimental data (gray circles) and model results (thin lines) of 200 simulations at $30^{\circ} \mathrm{C}$ (blue) and $60^{\circ} \mathrm{C}$ (red). The dark gray lines represent temperature-dependent isotopic equilibrium at $0-350^{\circ} \mathrm{C}$, and the thick red and blue lines show the median of the individual simulations, with tickmarks at $\Delta \mathrm{G}_{\text {net }}$ values of $-20,-30,-80$, and $-120 \mathrm{~kJ} \mathrm{~mol}^{-1}$. (A) $\Delta^{13} \mathrm{CH}_{3} \mathrm{D}$ against $\Delta^{12} \mathrm{CH}_{2} \mathrm{D}_{2}$. (B) $\Delta^{13} \mathrm{CH}_{3} \mathrm{D}$ against ${ }^{2} \varepsilon_{\mathrm{CH}_{4}-\mathrm{H}_{2} \mathrm{O}}$. (C) $\Delta^{13} \mathrm{CH}_{3} \mathrm{D}$ against ${ }^{13} \varepsilon_{\mathrm{CO}_{2}-\mathrm{CH}_{4}}$. Laboratory culture samples are from hydrogenotrophic methanogens that do not have membrane-associated methanophenazines.

constrain the energetic state of the cell (e.g., $\Delta^{13} \mathrm{CH}_{3} \mathrm{D}$ is $\approx 4 \%$ at both $\Delta \mathrm{G}_{\text {net }}$ of $\approx-20$ and $\approx-70$ $\mathrm{kJ} \mathrm{mol}^{-1}$ ). However, in combination with ${ }^{13} \varepsilon_{\mathrm{CO}_{2}-\mathrm{CH}_{4}}$ and ${ }^{2} \varepsilon_{\mathrm{CH}_{4}-\mathrm{H}_{2} \mathrm{O}}$ data, the position in the $\Delta \mathrm{G}_{\text {net }}$ landscape and the degree of departure from equilibrium may be uniquely constrained (Fig. 3). The multiple-isotope composition of methane may thus be a useful proxy for $\Delta \mathrm{G}_{\text {net }}$ in natural environments where measurements of $\mathrm{H}_{2}, \mathrm{CO}_{2}$ and $\mathrm{CH}_{4}$ concentrations are not easily obtainable. In addition to departure from equilibrium of the Mcr- and Mtr-catalyzed reactions, which may cause anti-clumped $\Delta^{12} \mathrm{CH}_{2} \mathrm{D}_{2}$ compositions, a testable prediction of our model is that the Hmd-catalyzed reaction may also cause anti-clumping. This arises from combinatorial effects (30-32) when Hmd activity is high, and especially during $\mathrm{H}_{2}-\mathrm{H}_{2} \mathrm{O}$ hydrogen isotopic disequilibrium (fig. S6).

The metabolic-isotopic model may be used to examine the controls on the isotopic fractionation of methanogenesis not only in laboratory cultures, but in natural environments as well. Laboratory cultures operate far from equilibrium, usually at $\mathrm{H}_{2}$ concentrations and cell-specific methanogenesis rates (csMR) much higher than those in natural environments (table S5; fig. S9). Recent reevaluations of slowly forming biogenic methane sources such as marine sediments, coalbeds or shale gas deposits, revealed that apparent $\mathrm{CH}_{4}-\mathrm{CO}_{2}$ and $\mathrm{CH}_{4}-\mathrm{H}_{2} \mathrm{O}$ isotopic equilibrium is common (8, 

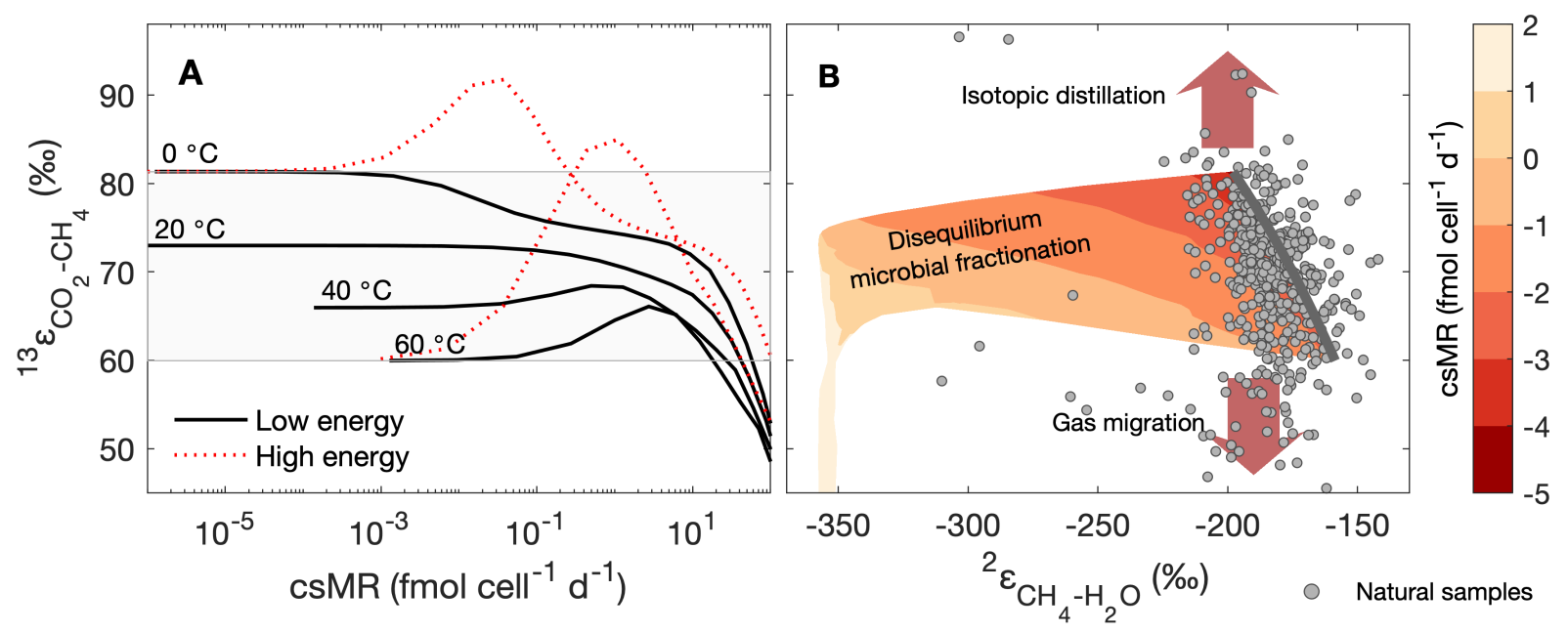

Figure 4: Isotopic fractionation during methanogenesis in energy-limited conditions. (A) ${ }^{13} \varepsilon_{\mathrm{CO}_{2}-\mathrm{CH}_{4}}$ against csMR. Dotted red lines show the laboratory-calibrated model (high energy) results for the same temperatures. (B) ${ }^{13} \varepsilon_{\mathrm{CO}_{2}-\mathrm{CH}_{4}}$ against ${ }^{2} \varepsilon_{\mathrm{CH}_{4}-\mathrm{H}_{2} \mathrm{O}}$. Contours are $\log _{10}(\mathrm{csMR})$ predicted by our model, between $0^{\circ} \mathrm{C}$ and $60^{\circ} \mathrm{C}$. The calculations are for $\left[\mathrm{H}_{2}\right]$ between $1 \mathrm{nM}$ and $5 \mu \mathrm{M},\left[\mathrm{CO}_{2}\right]$ and $\left[\mathrm{CH}_{4}\right]$ of $1 \mathrm{mM}$, and a cell volume of $1 \mu \mathrm{m}^{3}$. The circles are biogenic environmental samples from marine sediments, coalbed methane and natural gas deposits $(n=491)$.

$21,33-36)$. There are currently no laboratory cultures that reproduce the isotopic effects associated with these conditions. We modified the model to use enzyme activities that were measured in $\mathrm{H}_{2}$-limited laboratory cultures (SM) and assessed the resulting $\Delta \mathrm{G}_{\text {net }}-\mathrm{csMR}$-isotopic relations at $0-60^{\circ} \mathrm{C}$.

Existing estimates of environmental $\Delta \mathrm{G}_{\text {net }}$ are more positive than $-30 \mathrm{~kJ} \mathrm{~mol}^{-1}$ (table S5). However, the determination of $\Delta \mathrm{G}_{\text {net }}$ in natural environments is often difficult because of low and spatially heterogeneous in-situ $\mathrm{H}_{2}$ concentrations (37-39), and the actual range of $\Delta \mathrm{G}_{\text {net }}$ likely reflects this heterogeneity. As $\Delta \mathrm{G}_{\text {net }}$ determines the csMR (fig. S9), which is easier to measure, we henceforth discuss csMR-isotopic fractionation relations. In contrast to methanogenesis in lab cultures, we found that under energy-limited conditions, the Mtr-catalyzed reaction departs from equilibrium before the Mcr-catalyzed reaction (fig. S7). As a consequence, different csMR-fractionation relations emerge, most notably for ${ }^{13} \varepsilon_{\mathrm{CO}_{2}-\mathrm{CH}_{4}}$ (Fig. 4A). Instead of an increase in ${ }^{13} \varepsilon_{\mathrm{CO}_{2}-\mathrm{CH}_{4}}$ to larger-than-equilibrium values, ${ }^{13} \varepsilon_{\mathrm{CO}_{2}-\mathrm{CH}_{4}}$ remains approximately constant up to csMR of $\sim 10$ fmol cell ${ }^{-1} \mathrm{~d}^{-1}$. The reason for this apparent carbon isotopic equilibrium is the similar magnitude of the $\mathrm{EFF}$ and $\mathrm{KFF}$ of $\operatorname{Mtr}\left(17 \% \circ\right.$ and $16 \% \circ$ at $60^{\circ} \mathrm{C}$, respectively, SM). An environmental predic- 
tion of the above is that ${ }^{13} \varepsilon_{\mathrm{CO}_{2}-\mathrm{CH}_{4}}$ that differs measurably from ${ }^{13} \varepsilon_{\mathrm{CO}_{2}-\mathrm{CH}_{4}}^{\mathrm{eq}}$ indicates csMR higher than $\sim 10 \mathrm{fmol} \mathrm{cell}^{-1} \mathrm{~d}^{-1}$.

Analytically distinguishable departure of ${ }^{2} \varepsilon_{\mathrm{CH}_{4}-\mathrm{H}_{2} \mathrm{O}}$ from equilibrium occurs at csMR between $\sim 0.001$ and 0.1 fmol cell ${ }^{-1} \mathrm{~d}^{-1}$ (at $0^{\circ} \mathrm{C}$ and $60^{\circ} \mathrm{C}$, respectively; fig. S8B), and departure from clumped isotope equilibrium occurs over a similar range of csMR (fig. S8C, D). Thus, our model reveals that at csMR between 0.1 and $10 \mathrm{fmol} \mathrm{cell}^{-1} \mathrm{~d}^{-1}$, one might expect near-equilibrium ${ }^{13} \varepsilon_{\mathrm{CO}_{2}-\mathrm{CH}_{4}}$ concurrent with disequilibrium ${ }^{2} \varepsilon_{\mathrm{CH}_{4}-\mathrm{H}_{2} \mathrm{O}}$. The opposite situation (i.e., near-equilibrium ${ }^{2} \varepsilon_{\mathrm{CH}_{4}-\mathrm{H}_{2} \mathrm{O}}$ and disequilibrium $\left.{ }^{13} \varepsilon_{\mathrm{CO}_{2}-\mathrm{CH}_{4}}\right)$ is common in natural environments, though csMR is usually unknown (fig. S9). As previously suggested, this apparent hydrogen isotopic equilibrium concurrent with carbon isotopic disequilibrium may be explained by diffusive mixing of $\mathrm{CO}_{2}$ and $\mathrm{CH}_{4}$, isotopic (Rayleigh) distillation, or diagenetic isotope exchange without net methane production $(8$, $34,40,41$, Fig. 4B). If disequilibrium ${ }^{13} \varepsilon_{\mathrm{CO}_{2}-\mathrm{CH}_{4}}$ is explained as above rather than by microbial expression of KFFs, then the scarcity of data within the field representing disequilibrium microbial fractionation in Fig. 4B may reflect near-equilibrium isotopic fractionation during methanogenesis in energy-limited environments. This implies csMR lower than $\sim 0.001-0.1 \mathrm{fmol} \mathrm{cell}^{-1}$ $\mathrm{d}^{-1}$ (depending on temperature), consistent with almost all csMR estimated from cell abundances and volumetric methanogenesis rates (SM, table S6). In energy-limited environments with higher csMR, near-equilibrium ${ }^{2} \varepsilon_{\mathrm{CH}_{4}-\mathrm{H}_{2} \mathrm{O}}$ concurrent with disequilibrium ${ }^{13} \varepsilon_{\mathrm{CO}_{2}-\mathrm{CH}_{4}}$ may be explained by methane cycling or anaerobic oxidation of methane that operates close to the thermodynamic limit (42).

By accounting for the metabolites and reactions in the hydrogenotrophic methanogenesis pathway, we link environmental substrate and product concentrations, $\mathrm{pH}$ and temperature to the energetics and net rate of methanogenesis, and to the associated fractionation of carbon, hydrogen and clumped isotopes. The landscape of departure of individual reactions in the pathway from reversibility controls these fractionations, explaining rate-fractionation relations in laboratory cultures, and highlighting the potential of multiple-isotope measurements of biogenic methane (carbon, hydrogen and clumped) as probes of the in-situ energetics of methanogenic activity. 
202

\section{Acknowledgments}

J.G. acknowledges support from the Sustainability and Energy Research Initiative (SAERI) of the Weizmann Institute of Science. Q.J. is supported by NSF award EAR-1636815.

\section{Author contributions}

J.G. and I.H. conceived the study, developed and analyzed the metabolic-isotopic model, and wrote the initial draft. Q.J. developed the metabolic model. All authors contributed to the writing.

\section{References}

1. M. Saunois et al., Earth Syst. Sci. Data 8, 697-751, ISSN: 1866-3516 (Dec. 2016).

2. S. Schwietzke et al., Nature 538, 88-91, ISSN: 0028-0836 (Oct. 2016).

3. Z. Lyu, N. Shao, T. Akinyemi, W. B. Whitman, en, Current Biology 28, R727-R732, ISSN: 0960-9822 (July 2018).

4. M. J. Whiticar, Chem. Geol. 161, 291-314, ISSN: 00092541 (Sept. 1999).

5. E. G. Nisbet et al., Glob. Biogeochem. Cycles 30, 1356-1370, ISSN: 08866236 (Sept. 2016).

6. D. A. Stolper et al., Geochim. Cosmochim. Acta 126, 169-191, ISSN: 00167037 (Feb. 2014).

7. D. T. Wang et al., Science 348, 428-431, ISSN: 1095-9203 (Apr. 2015).

8. T. Okumura et al., Prog. Earth Planet. Sci. 3, 14, ISSN: 2197-4284 (Dec. 2016).

9. X. Cao, H. Bao, Y. Peng, Geochim. Cosmochim. Acta 249, 59-75, ISSN: 0016-7037 (Jan. 2019).

10. J. Bassham, G. Krause, en, Biochim. Biophys. Acta BBA - Bioenerg. 189, 207-221, ISSN: 0005-2728 (Oct. 1969).

11. D. A. Beard, H. Qian, PloS One 2, e144, ISSN: 1932-6203 (Jan. 2007).

12. E. Noor, A. Flamholz, W. Liebermeister, A. Bar-Even, R. Milo, FEBS Lett. 587, 2772-7 (Sept. 2013). 
13. C. Rees, Geochim. Cosmochim. Acta 37, 1141-1162, ISSN: 00167037 (May 1973).

14. B. A. Wing, I. Halevy, Proc. Natl. Acad. Sci. U. S. A. 111, 18116-25, ISSN: 1091-6490 (Dec. 2014).

15. D. L. Valentine, A. Chidthaisong, A. Rice, W. S. Reeburgh, S. C. Tyler, Geochim. Cosmochim. Acta 68, 1571-1590, ISSN: 00167037 (Apr. 2004).

16. H. Penning, C. M. Plugge, P. E. Galand, R. Conrad, Glob. Change Biol. 11, 2103-2113, ISSN: 1354-1013 (Dec. 2005).

17. K. Takai et al., Proc. Natl. Acad. Sci. U. S. A. 105, 10949-54, ISSN: 1091-6490 (Aug. 2008).

18. S. Hattori et al., Geochem. J. 46, 193-200, ISSN: 00167002 (2012).

19. B. D. Topçuoğlu, C. Meydan, T. B. Nguyen, S. Q. Lang, J. F. Holden, Appl. Environ. Microbiol. 85, 1-14, ISSN: 0099-2240 (Mar. 2019).

20. S. Scheller, M. Goenrich, R. K. Thauer, B. Jaun, J. Am. Chem. Soc. 135, 14975-84, ISSN: 1520-5126 (Oct. 2013).

21. J. Gropp, M. A. Iron, I. Halevy, en, Geochimica et Cosmochimica Acta 295, 237-264, ISSN: 0016-7037 (Feb. 2021).

22. H. M. Miller et al., Geochim. Cosmochim. Acta 237, 18-31, ISSN: 00167037 (June 2018).

23. D. B. Nothaft et al., en, J. Geophys. Res. Biogeosciences NA, e2020JG006025, ISSN: 21698961 (2021).

24. H. Yoshioka, S. Sakata, Y. Kamagata, Geochim. Cosmochim. Acta 72, 2687-2694, ISSN: 00167037 (2008).

25. S. Kawagucci et al., Geochim. Cosmochim. Acta 142, 601-614, ISSN: 00167037 (Oct. 2014).

26. C. Afting, E. Kremmer, C. Brucker, A. Hochheimer, R. K. Thauer, Arch. Microbiol. 174, 225-232, ISSN: 0302-8933 (Sept. 2000).

27. R. Botz, H. D. Pokojski, M. Schmitt, M. Thomm, Org. Geochem. 25, 255-262, ISSN: 01466380 (1996).

28. P. M. Douglas et al., Org. Geochem. 113, 262-282, ISSN: 01466380 (Nov. 2017).

29. D. A. Stolper et al., Geochim. Cosmochim. Acta 161, 219-247, ISSN: 00167037 (July 2015). 
30. L. Y. Yeung, Geochim. Cosmochim. Acta 172, 22-38, ISSN: 00167037 (Jan. 2016).

31. T. Röckmann, M. E. Popa, M. C. Krol, M. E. G. Hofmann, Sci. Rep. 6, 31947, ISSN: 20452322 (Oct. 2016).

32. L. Taenzer et al., en, Geochimica et Cosmochimica Acta 285, 225-236, ISSN: 0016-7037 (Sept. 2020).

33. D. S. Vinson et al., Chem. Geol. 453, 128-145, ISSN: 00092541 (2017).

34. A. C. Turner et al., en, Geochimica et Cosmochimica Acta NA, NA, ISSN: 0016-7037 (Apr. 2021).

35. J. J. Jautzy, P. M. J. Douglas, H. Xie, J. M. Eiler, I. D. Clark, en, Earth and Planetary Science Letters 562, 116841, ISSN: 0012-821X (May 2021).

36. N. Zhang et al., en, Geochimica et Cosmochimica Acta NA, NA, ISSN: 0016-7037 (Aug. 2021).

37. R. Conrad, T. J. Phelps, J. G. Zeikus, Appl. Environ. Microbiol. 50, 595-601, ISSN: 00992240 (Sept. 1985).

38. E. Giraldo-Gomez, S. Goodwin, M. S. Switzenbaum, Biotechnol. Bioeng. 40, 768-76, ISSN: 0006-3592 (Oct. 1992).

39. Y.-S. Lin et al., en, Geochimica et Cosmochimica Acta 77, 186-201, ISSN: 0016-7037 (Jan. 2012).

40. C. K. Paull et al., Proc. Ocean Drill. Program Sci. Results 164, 67-78 (2000).

41. J. W. Pohlman, M. Kaneko, V. B. Heuer, R. B. Coffin, M. Whiticar, en, Earth and Planetary Science Letters 287, 504-512, ISSN: 0012-821X (Oct. 2009).

42. G. Wegener, J. Gropp, H. Taubner, I. Halevy, M. Elvert, en, Sci. Adv. 7, eabe4939, ISSN: 2375-2548 (May 2021). 